Research Article

\title{
Fault Detection for the Scraper Chain Based on Vibration Analysis Using the Adaptive Optimal Kernel Time-Frequency Representation
}

\author{
Xing Zhang $\mathbb{D}^{1,2}$ Wei Li $\mathbb{D}^{1,2}$ Zhencai Zhu, $^{1,2}$ Shanguo Yang, ${ }^{1,2}$ and Fan Jiang $\mathbb{D}^{1,2}$ \\ ${ }^{1}$ School of Mechatronic Engineering, China University of Mining and Technology, Xuzhou 221116, China \\ ${ }^{2}$ Jiangsu Key Laboratory of Mine Mechanical and Electrical Equipment, China University of Mining and Technology, \\ Xuzhou 221116, China
}

Correspondence should be addressed to Wei Li; liwei_cmee@163.com

Received 14 April 2019; Accepted 13 June 2019; Published 24 July 2019

Academic Editor: Chao Tao

Copyright (C) 2019 Xing Zhang et al. This is an open access article distributed under the Creative Commons Attribution License, which permits unrestricted use, distribution, and reproduction in any medium, provided the original work is properly cited.

A scraper conveyor is a key component of large-scale mechanized coal mining equipment, and its failure patterns are mainly caused by chain jam and chain fracture. Due to the difficulties with direct measurement for multiple performance parameters of the scraper chain, this paper deals with a novel strategy for fault detection of the scraper chain based on vibration analysis of the chute. First, a chute vibration model (CVM) is applied for modal analysis, and the hammer impact test (HIT) is conducted to validate the accuracy of the CVM; second, the measuring points for vibration analysis of the chute are determined based on the modal assurance criterion (MAC); and third, to simulate the actual vibration properties of the chute, a dynamic transmission system model (DTSM) is constructed based on finite element modeling. The fixed-point experimental testing (FPET) is then conducted to indicate the correctness of simulation results. Subsequently, the DTSM-based vibration responses of the chute under different operating conditions are obtained. In this paper, the proposed strategy is employed to determine the occurrence of chain faults by amplitude comparisons, while failure patterns are distinguished by the adaptive optimal kernel time-frequency representation (AOKR).

\section{Introduction}

A scraper conveyor is a piece of continuous mechanical transport equipment with a chain-type traction for transporting bulk materials in coal mining face [1]. As Figure 1 describes, the transmission system of the scraper conveyor is a complex system with multiple bodies that mainly comprise sprockets, scrapers, scraper chains, and chutes. It operates as a closed loop by linking the scraper chains together, and the scraper chains run around the sprockets. In chain assembly failures, most malfunctions mainly involve jam and fracture of the scraper chains. Main causes for the jam and fracture failures of the scraper chains include the following aspects: uneven loads on the chutes [2], overlong laying length of the scraper conveyor [3, 4], and complex interactions between the core components of the chain assembly $[5,6]$. In order to monitor the working state of the scraper conveyor, there is an urgent need for fault detection of the scraper chains.

Since the performance of the scraper chains can directly determine the reliability and stability of the scraper conveyor to a great extent, such issues about the dynamic characteristics of the scraper chains have been examined in several previous studies. Generally speaking, research approaches include two major categories, i.e., model-based methods and experimental methods. For example, Nie et al. [7] presented an Euler method-based approach to model a large-scale scraper conveyor and evaluate the dynamic characteristics of the transmission system. Jiang et al. [8] established rigid and rigid-flexible coupling models of the chain assembly to analyze their complex dynamic behavior. Myszkowski et al. [9] designed a mobile measuring system to measure essential operating parameters to study the system behavior of the chain-driven machines. Wang et al. 


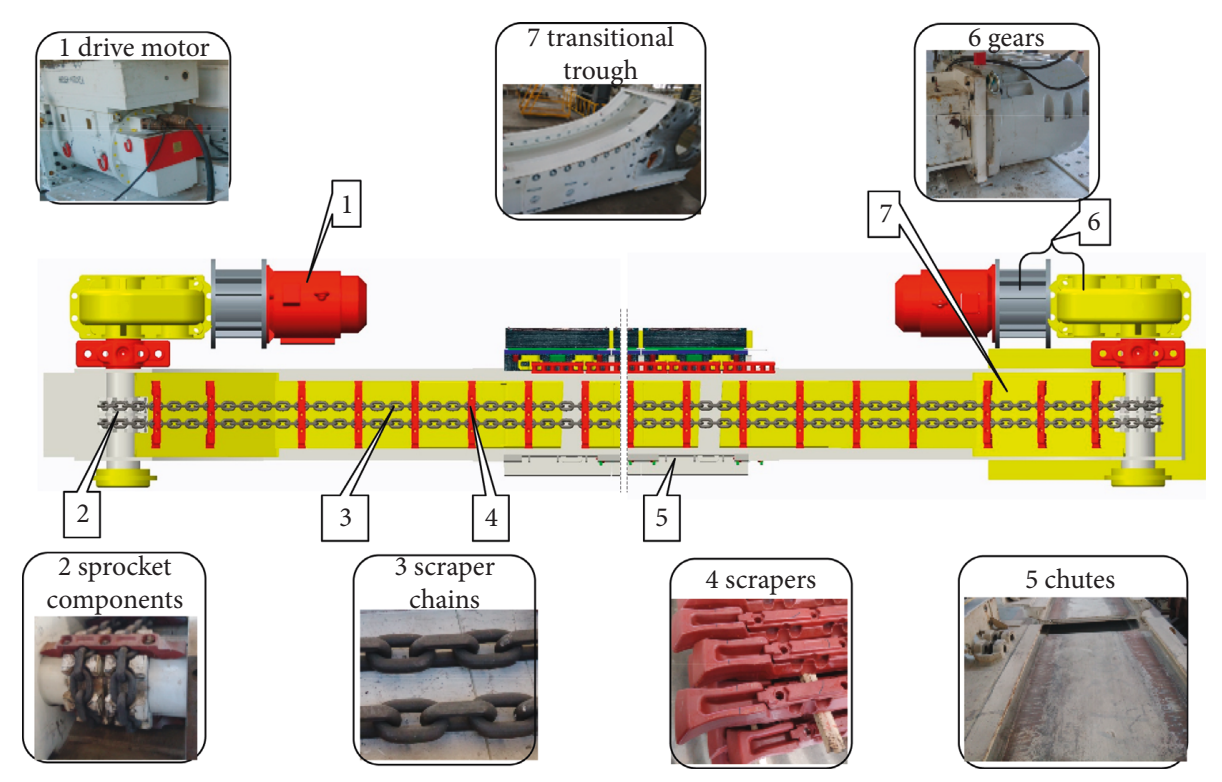

FIgURE 1: Transmission system of the scraper conveyor.

[10] developed a dynamic tension test system for monitoring the dynamic tension of a heavy scraper conveyor based on microstrain detection. Obviously, previous studies have largely concentrated on direct measurement and analysis for parameters of the moving scraper chain. However, the mentioned applications of model-based methods stop proceeding at the level of idealized hypothesis. Currently, due to installation difficulties of multiple sensors, most of the experimental methods are not suitable for actual engineering. Considering limitations of harsh conditions in coal mines, the traditional mobile parameter measurement of the scraper chain is difficult and a fix-point measurement method is preferred. Moreover, the scraper chain moves continuously along the chutes, and the dynamic and vibration properties of the chutes can effectively reflect the working state of the scraper chain. Therefore, the fix-point vibration analysis of the chute is performed in our work, which lays a foundation for fault detection of the scraper chain.

In the recent scientific literature, scholars have conducted preliminary research on fault detection of the scraper conveyor. Most of the latest studies focus on theoretical design more than practical strategy, such as fuzzy fault tree [11], Bayesian network [12], fuzzy neural network [13], and rough set theory [14]. Comparatively speaking, fault detection strategy based on vibration analysis has attracted much attention over the past decade. Zhang et al. [15] detected crack faults of a lubricant-level viewport and upper viewport of a high-speed railway train gear box through vibration tests. Parloo et al. [16] presented a sensitivity-based damage assessment technique for autonomous condition monitoring of a slat track of a commercial Airbus A320 aircraft. Sakaris et al. [17] introduced the random-vibration-based method for damage detection and precise localization on a lab-scale aircraft stabilizer structure. To date, few studies have been performed on fault detection for the scraper chain based on vibration analysis.

For the purpose of fault detection for the scraper chain, the novelty of our study is represented by vibration analysis of the chute under various working conditions. In this paper, modal analysis is performed in two ways: numerically, based on the CVM, and experimentally, based on the HIT. According to the results of model analysis, the MAC is applied for the optimal placement of acceleration sensors and three measuring points on the chute are chosen for vibration detection. Sequentially, the DTSM is built and serves to study the vibration properties of the actual chute, and the correctness of the DTSM is verified by the experimental study of the FPET. Furthermore, the transient responses of different measuring points on the fourth chute of the DTSM are obtained under three working conditions, which are normal condition, chain jam, and chain fracture, respectively. Besides, the effects of different external loads on vibration properties are also discussed. We propose the novel strategy that allows for fault detection of the scraper chain, which include two aspects: on the one hand, the occurrence of chain faults can be detected by amplitude comparisons of the vibration signals; on the other hand, the fault patterns can be distinguished by the AOKR.

The main contributions of our work can be summarized as follows: (1) an optimal placement scheme of acceleration sensors is proposed based on the MAC to determine the measuring points on the chute for vibration analysis; (2) a DTSM is constructed through finite element modeling to simulate the working state of the actual chute under different operating conditions; and (3) to detect chain faults of the scraper chain, a novel strategy is proposed by a combination of amplitude comparisons and the AOKR.

The paper is organized in the following way: Section 2 provides the theory basis of the proposed fault detection 
strategy. Section 3 illustrates modal analysis of the chute and presents details of the construction of the DTSM. The optimal placement scheme of acceleration sensors is presented in Section 4, and then the proposed strategy of fault detection is implemented. Finally, Section 5 provides some concluding remarks.

\section{Research Methodology of the Proposed Strategy}

2.1. Modal Assurance Criterion. The modal analysis theory is adapted to analyze and evaluate intrinsic dynamic properties of the mechanical structure, and it also serves as the premise of vibration analysis [18]. The vibration properties of a structure are usually described by modal parameters, which is the most fundamental content of vibration analysis. Since most of the linear systems can be discretized into an elastic system with $n$ degrees of freedom (DOFs), we can express the motion differential equation of the chute by $n$ coordinates as

$$
\begin{gathered}
M \delta^{\prime \prime}(t)+D_{\mathrm{P}} \delta^{\prime}(t)+K \delta(t)=B f(t), \\
y=C_{\mathrm{d}} \delta(t)+C_{\mathrm{v}} \delta^{\prime}(t)+D f(t),
\end{gathered}
$$

where $M, D_{\mathrm{P}}, K$, and $B \in R^{n \times n}$ denote the mass matrix, damping matrix, stiff matrix, and sensor position matrix, respectively. $f(t)$ and $\delta(t) \in R^{n \times 1}$ denote the force vector and displacement vector, respectively. $y \in R^{m \times 1}$ denotes the measurement vector, and $m$ denotes the number of the sensors. $C_{\mathrm{d}}, C_{\mathrm{v}}$, and $D$ denote the output coefficient matrices. To perform modal analysis of the chute, the damping parameters will not affect the characteristics of the natural frequency and its corresponding vibration mode, so we suppose the influence of the damping coefficient can be ignored. When $f(t)=0$, equation (1) takes the linear and homogeneous form:

$$
M \delta^{\prime \prime}(t)+K \delta(t)=0 .
$$

To obtain the natural frequencies and mode shapes of the chute, the solution of equation (3) is equivalent to solving the generalized eigenvalues and eigenvectors. The vibrational shape is formed by the superposition of multiple modes, and then $\delta(t)$ can be represented as

$$
\delta(t)=\sum_{i=1}^{n} \phi_{i} \eta_{i}=\phi \eta
$$

where $\phi=\left[\phi_{1}, \phi_{2}, \ldots \phi_{n-1}, \phi_{n}\right]$ and $\eta=\left[\eta_{1}, \eta_{2}, \ldots\right.$ $\left.\eta_{n-1}, \eta_{n}\right]^{T}$ denote the modal shape matrix and modal coordinate matrix, respectively. $\phi_{i}$ and $\eta_{i}$ represent the modal vector and modal coordinate of mode $i$, respectively. When conducting modal experiments, the research usually focuses on the first $n_{t}\left(n_{t}<n\right)$ modes. Then, equations (1) and (2) can be expressed as

$$
\begin{aligned}
& \eta_{i}^{\prime \prime}+2 \zeta_{i} \omega_{i} \eta_{i}^{\prime}+\omega_{i}^{2} \eta_{i}= \phi_{i}^{T} B f(t)=\Gamma_{i} f(t), \\
&\left(i=1,2,3, \ldots, n_{t}\right), \\
& y_{\mathrm{d}}=\sum_{i=1}^{n_{t}} C_{\mathrm{d}} \phi_{i} \eta_{i}+\sum_{i=1}^{n_{t}} C_{\mathrm{v}} \phi_{i} \eta_{i}^{\prime}+D f(t) \\
&=\sum_{i=1}^{n_{t}} \bar{C}_{\mathrm{di}} \eta_{i}+\sum_{i=1}^{n_{t}} \bar{C}_{\mathrm{vi}} \eta_{i}^{\prime}+D f(t),
\end{aligned}
$$

where $\bar{C}_{\mathrm{di}}, \bar{C}_{\mathrm{vi}}$, and $\Gamma_{i}$ denote the influence coefficient vectors of displacement, velocity, and sensors, respectively. $\zeta_{i}$ and $\omega_{i}$ denote the modal damping ratio and frequency. Limited by structural configuration of the chute and the field conditions, the installation of sensors can directly determine the validity of experimental data. While considering the economic problem, the layout scheme should also ensure that the dynamic characteristic information of the structure can fully be obtained. With the determination of $\Gamma_{i}$, more independent and accurate modal information can be measured by a limited number of sensors. In our study, the modal assurance criterion (MAC) [19] is applied to determine the optimal installation positions and most reasonable number of sensors. The MAC has strong applicability in evaluating the angle between different vibration vectors, and the influence of the mass matrix and stiffness matrix of the structure can be neglected. The elements of the MAC matrix take the following form:

$$
\operatorname{MAC}_{i j}=\frac{\left(\phi_{i}^{T} \cdot \phi_{j}\right)^{2}}{\left(\phi_{i}^{T} \cdot \phi_{i}\right)\left(\phi_{j}^{T} \cdot \phi_{j}\right)} \in[0,1], \quad(i \neq j),
$$

where $\phi_{i}$ and $\phi_{j}$ can be obtained by using equation (4). Theoretically, the natural vibration modes of different nodes are orthogonal to each other.

However, the actual measured modal vectors are difficult to guarantee the orthogonality. The placement of sensors must ensure a large space angle between the modal vectors of the measuring points so as to retain the original model features to the greatest extent. The numerical variation ranges of the off-diagonal element $\mathrm{MAC}_{i j}$ represent the following statements: for $\mathrm{MAC}_{i j}=0$, the modal vectors are orthogonal to each other; for $\mathrm{MAC}_{i j}<0.25$, the modal vectors are easily distinguishable; for $\mathrm{MAC}_{i j}=1$, the space angle between the modal vectors is 0 and the modal vectors are indistinguishable. According to the MAC, a smaller $\mathrm{MAC}_{i j}$ makes it easier to distinguish different modal vectors, which also indicates a better performance of the optimal placement scheme. Hence, the installation position and number of sensors should be determined to minimize the off-diagonal elements of the MAC matrix. The minimum value is given by

$$
f=\max \left|\mathrm{MAC}_{i j}\right|, \quad(i \neq j) .
$$

\subsection{Adaptive Optimal Kernel Time-Frequency Representation.} The vibration signals caused by chain faults belong to nonstationary random signals. Based on time-frequency 
analysis theory, the main tools dedicated to the study of nonstationary signals are available. A commonly used timefrequency distribution is the Wigner-Ville distribution (WVD), which has found many successful applications in different areas $[20,21]$. The input signal in the time domain is denoted by using $s(t)$, and the definition of WVD can be given by

$$
D_{\mathrm{WV}}(t, \omega)=\int s\left(t+\frac{\tau}{2}\right) s^{*}\left(t-\frac{\tau}{2}\right) e^{-j \omega \tau} d \tau,
$$

where $\omega$ denotes the frequency variable and $s^{*}(t)$ is the conjugate function of $s(t)$. Then, equation (8) can be converted into the time-frequency distribution function as

$$
A(\theta, \tau)=\int s\left(t+\frac{\tau}{2}\right) s^{*}\left(t-\frac{\tau}{2}\right) e^{j \theta t} d t
$$

where $\theta$ and $\tau$ denote the fuzzy-domain variables. Based on equations (8) and (9), we get

$$
\begin{aligned}
D_{\mathrm{WV}}(t, \omega) & =\frac{1}{2 \pi} \iint A(\theta, \tau) e^{-j \theta t-j \omega \tau} d \theta d \tau, \\
A(\theta, \tau) & =\iint D_{\mathrm{WV}}(t, \omega) e^{j \theta t+j \omega \tau} d t d \omega .
\end{aligned}
$$

Developed from WVD, the Cohen class bilinear distributions are the commonly used time-frequency analysis methods and can be expressed as

$$
P(t, \omega)=\frac{1}{2 \pi} \iint A(\theta, \tau) \phi(\theta, \tau) e^{-j \theta t-j \omega \tau} d \theta d \tau,
$$

where $A(\theta, \tau)$ denotes the ambiguity function and $\phi(\theta, \tau)$ denotes the kernel function. Bilinear time-frequency analysis such as WVD exhibits a high time-frequency resolution, whereas it is contaminated by serious cross-terms. Then the AOKR is applied to suppress the cross-term interferences caused by multicomponents [22]; meanwhile, the modified ambiguity function is defined as

$$
\begin{aligned}
A_{1}(t, \theta, \tau)= & \int s^{*}\left(u-\frac{\tau}{2}\right) \omega^{*}\left(u-t-\frac{\tau}{2}\right) s\left(u+\frac{\tau}{2}\right) \\
& \times \omega\left(u-t+\frac{\tau}{2}\right) e^{j \theta u} d u,
\end{aligned}
$$

where $\omega(u)$ denotes the symmetric window function. For any $A_{1}(t, \theta, \tau)$, we can get the corresponding adaptive optimal kernel function $\phi_{\text {opt }}(t, \theta, \tau)$. Under the premise of ensuring high resolution, the AOKR shows good performance to analyze vibration signals of the chute under different working conditions. The adaptive optimal kernel time-frequency distribution is expressed as

$$
P_{\mathrm{AOK}}(t, \omega)=\frac{1}{2 \pi} \iint A_{1}(t, \theta, \tau) \phi_{\mathrm{opt}}(t, \theta, \tau) e^{-j \theta t-j \omega \tau} d \theta d \tau .
$$

\section{Finite Element Modeling}

3.1. Modal Analysis. The CVM shown in Figure 2(a) is established in the software ANSYS and designed to be faithful to the actual device. In fact, the CVM is a typical multibody dynamics system that consists of the chute, plat chains, vertical chains, and scrapers; the dimension of scraper chains is $\varphi 48 \times 152(\mathrm{~mm})$, and the CVM contains 773,782 elements and 1,117,993 nodes. Referring to Figure 2(a), to describe the interactions between different components, the kinematic restriction mainly includes the following two aspects: kinematic constraints and contact relations. The inertial coordinate system I works as the reference of the system frame and is applied to determine the location of different components, and contact pairs occur between two bodies moving correspondingly to each other. The vibration signals of the chute can be expressed as the sum of natural vibration modes of each order, and the lower order vibration modes have a greater correlation with the vibration properties. To obtain intrinsic properties of the chute, we extract the first 6-order natural frequencies of the CVM for modal analysis, which would facilitate further studies on the optimal placement of the acceleration sensors.

The natural frequencies of the chute are obtained by finite element analysis (FEA) of the CVM and experimental modal analysis (EMA) through the HIT. As shown in Figure 2(b), the HIT is performed with the use of an impact hammer (LC02) and an acceleration sensor (TST120A1000), which is conducted for vibration measurements of the actual chute. The exciting point is impacted by using the impact hammer to trigger vibration signals, and then the acceleration sensor mounted on the surface of the shovel coal board is used to pick up the vibration response. Besides, the wireless acquisition device is utilized for collection and transmission of the experimental data, which is detailed in Section 4.2. Thus, we get the exciting force and vibration response as shown in Figure 3.

Through model simulation, we get the modal displacement contours of the first 6-order natural vibration modes of the chute (Figure 4). According to the HIT, natural frequencies of the actual chute are extracted from the experimental modal curve, and each peak of the response curve is corresponding to a vibration mode. As listed in Table 1, comparisons between natural frequencies of the first 6-order natural vibration modes based on FEA and EMA are made. In addition, the error $\psi_{i}$ is defined as $\psi_{i}=\left|\left(\alpha_{i}-\beta_{i}\right) / \beta_{i}\right|$ ( $i=1 \sim 6$ ), where $\alpha_{i}$ and $\beta_{i}$ denote the natural frequency derived from FEA and EMA, respectively. In Table 1, the errors show low values for each mode. In particular, the maximum error between the simulation results and experimental results is $13.30 \%$, and the minimum $\psi_{i}$ is almost $2.32 \%$. The mentioned errors indicate the superiority of the established CVM.

3.2. Construction of the DTSM. In actual operation, the scraper chain is driven by using drive motors and moves continuously along the chutes, and its reliability is directly related to the working performance of the transmission system. Figure 5 describes the dynamic transmission system model (DTSM) built by using the transient analysis module in ANSYS. The primary goal of construction of the DTSM is to achieve an accurate dynamic model, which would facilitate further studies on the vibration behavior of the actual 


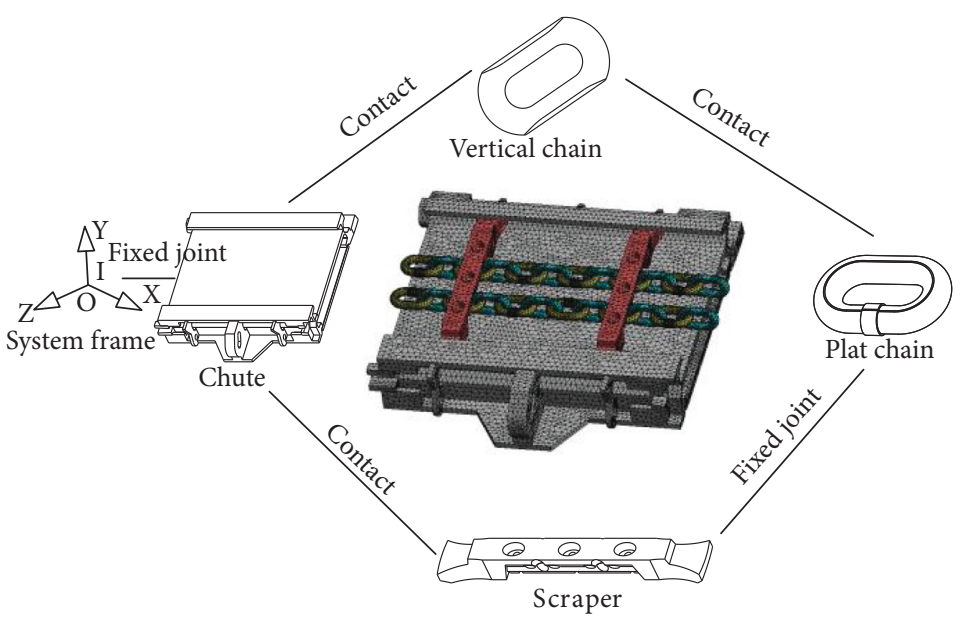

(a)

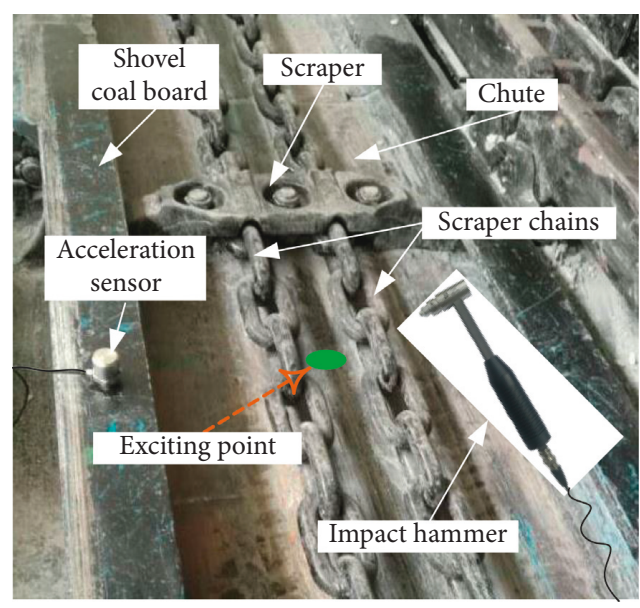

(b)

FIgure 2: Descriptions of modal analysis based on (a) the CVM and (b) the HIT.

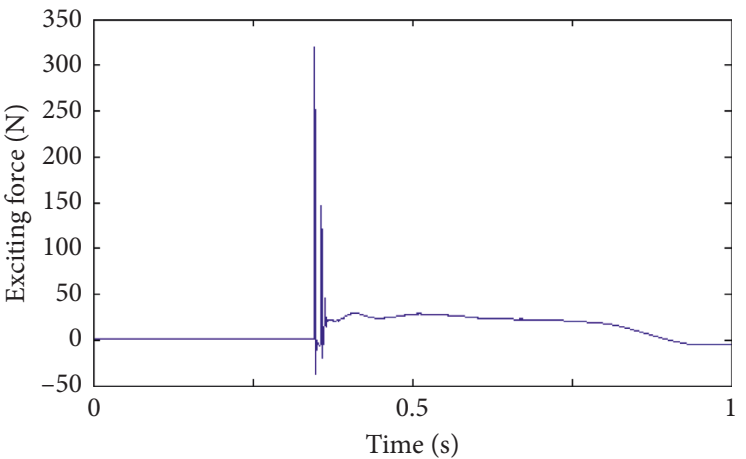

(a)

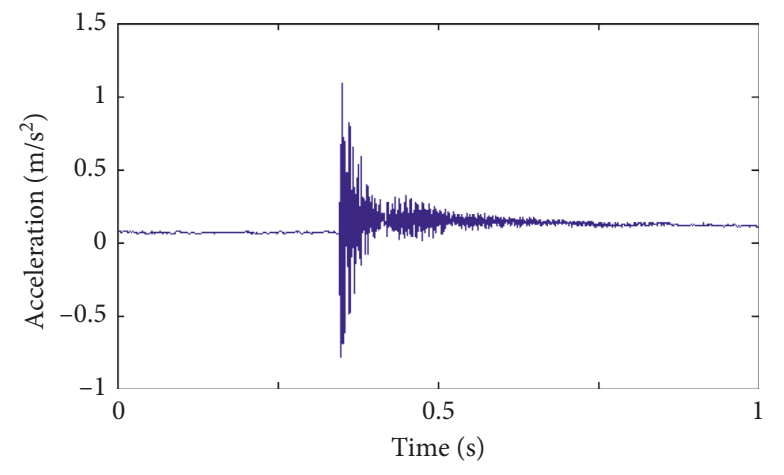

(b)

Figure 3: Exciting force and the vibration response.

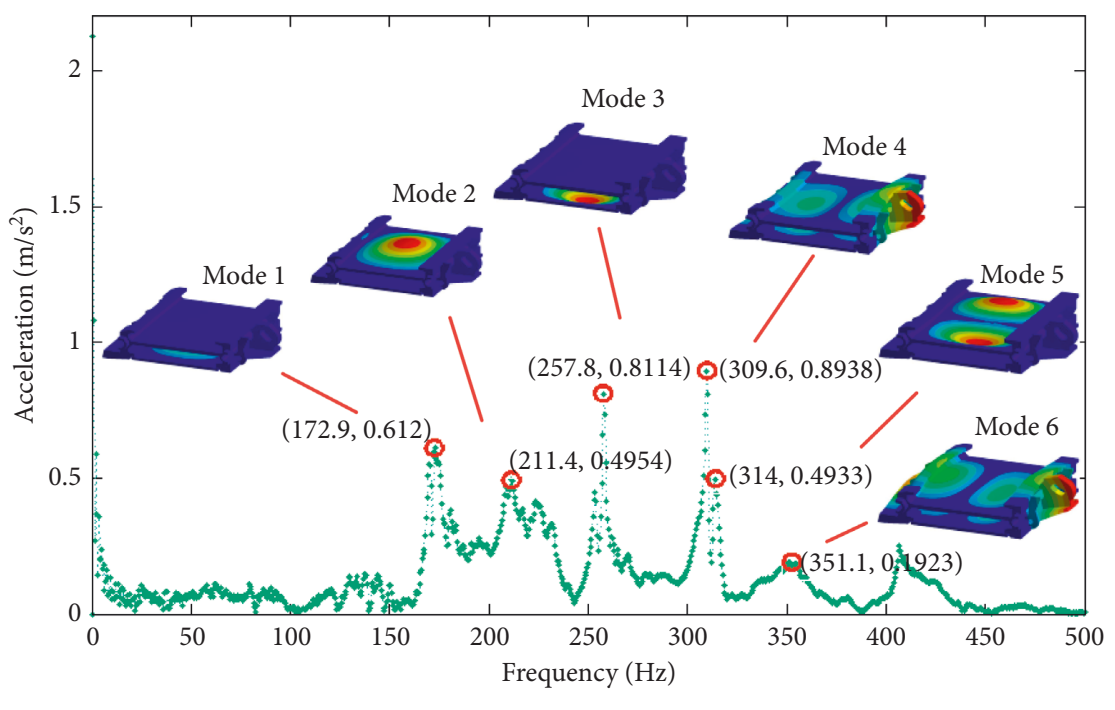

..... Experimental modal

FIGURE 4: Vibration modes of the chute. 
TABLE 1: Frequency response of vibration signals.

\begin{tabular}{lccc}
\hline Mode no. & FEA $(\mathrm{Hz})$ & EMA $(\mathrm{Hz})$ & $\psi_{i}(\%)$ \\
\hline 1 & 177.54 & 172.9 & 2.68 \\
2 & 183.29 & 211.4 & 13.30 \\
3 & 287.45 & 257.8 & 11.50 \\
4 & 302.42 & 309.6 & 2.32 \\
5 & 328.68 & 314.0 & 4.68 \\
6 & 341.97 & 351.1 & 2.60 \\
\hline
\end{tabular}

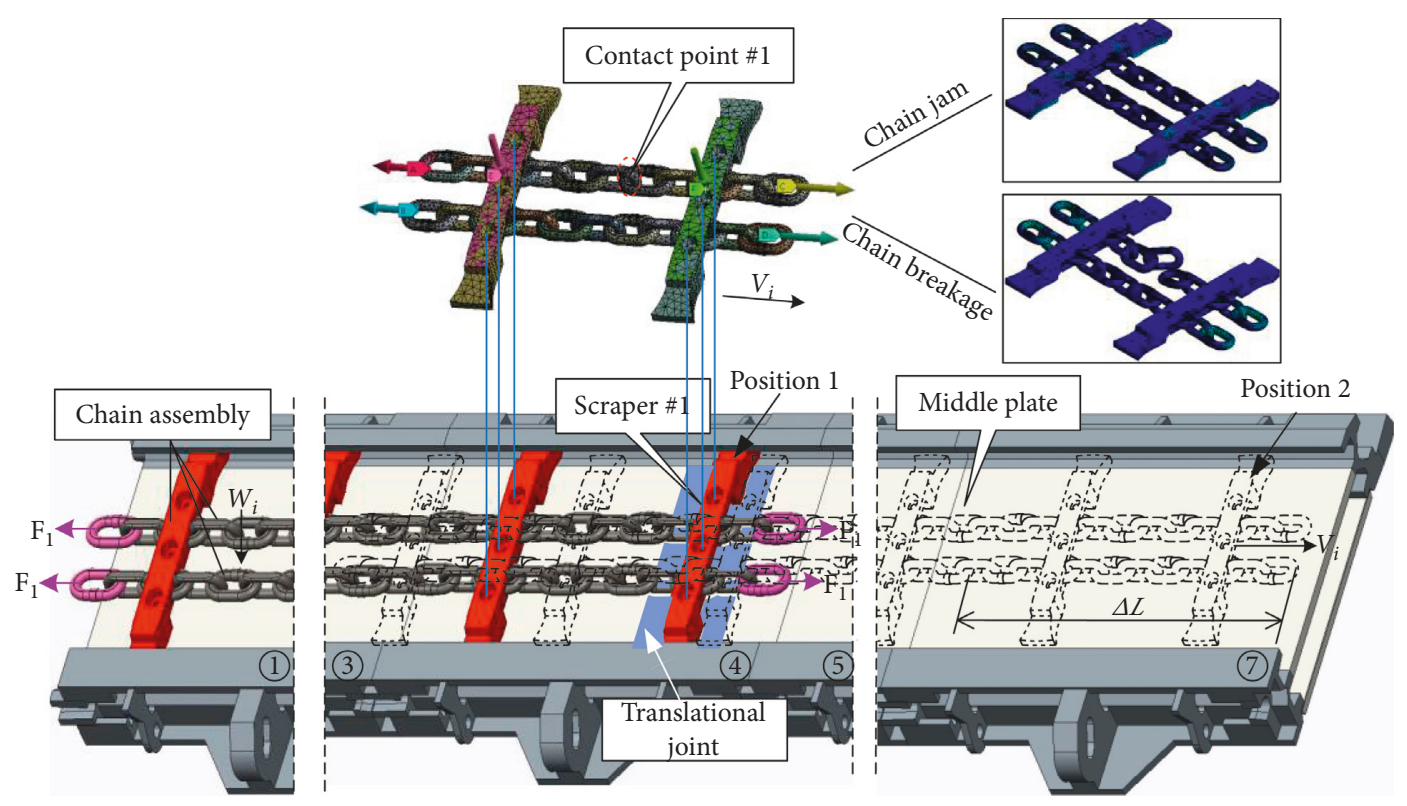

FIgURE 5: Simulation process of the DTSM.

chute without carrying out physical tests. The simulation parameters and kinematic restriction of the DTSM are consistent with the CVM in Figure 2(a). To illustrate this issue in more detail, the frictional contacts are set between the vertical chains and the chutes and between the scrapers and chutes. Correspondingly, the bonded contacts are set between the plat chains and the vertical chains. The dynamic model mainly contains two prominent parts: the chain assembly and the chutes. Wherein, the chain assembly is composed of the scrapers and scraper chains and can be equally divided into multiple segments of length $\Delta L$; the number of the chutes is 7 , and they are marked as shown in Figure 5. A translational joint is set between scraper \#1 and the middle plate, based on which the chain assembly can run along the chutes at a transmission speed of $V_{i}$. Moreover, the pretightening force and external load of the dynamic model are defined as $F_{1}$ and $W_{i}$, respectively. Here, we set $F_{1}=796.12 \mathrm{kN}$. In Figure 5, the pretightening force is applied at the two ends of the chain assembly, which can ensure that the scraper chain remains tight during the movement. The external load $W_{i}$ is applied on the upper surface of the scrapers and middle plates, and the material density in the chute under the full-load condition is $W_{0}$, where $W_{0}=694 \mathrm{~kg} / \mathrm{m}$.

\section{AOKR-Based Fault Detection Strategy of the Scraper Chain}

Considering that the scraper conveyor is susceptible to frequent loading, excessive bending, and artificial misconduct in actual engineering, different patterns of chain faults usually act on the scraper chain. The failure patterns will cause abnormal vibration of the chute. Actually, direct measurement and analysis for parameters of the moving scraper chain is difficult, which raises a contradiction between practical engineering requirements and the installation limitations of multiple sensors. In order to detect chain faults promptly, the fix-point vibration measurement of the measuring points for the chute is considered instead of mobile parameter measurement for the scraper chain. In this section, the DTSM is utilized to acquire the vibration properties of the actual chute under various working conditions, and the FPET of the vibration signals is conducted to validate the accuracy of the dynamic model. The fundamental idea of our proposed strategy is to determine the occurrence of chain faults by amplitude comparisons, and then fault signals are analyzed through the AOKR to distinguish the fault patterns. 
4.1. Optimal Placement of the Acceleration Sensors. Before conducting the FPET, the installation scheme of the acceleration sensors should be determined to ensure the validity of the measured vibration signals and the economy of the experimental process. Based on modal analysis of the FEA (Figure 2(a)), we extract 20 nodes from the chute as the primary measuring points, which are labeled in Figure 6(a). According to the theory of MAC, the total modal displacements of the selected 20 points serve as the inputs of equations (6) and (7). In Figure 6(b), the curve reveals change rules of the minimum $\mathrm{MAC}_{i j}$ for different number of sensors.

To illustrate the optimal placement scheme of acceleration sensors in more detail, the optimum installation positions for different number of sensors are shown in Table 2. Accordingly, the vibration response of the actual chute should be recorded by 3 acceleration sensors, and the optimum installation positions are set at nodes 3,9 , and 16 , respectively.

4.2. Experimental Evaluations. According to Section 3.2, the simulation process of the DTSM is performed under normal condition without a load, and the transmission speed $V_{i}$ is set as $V_{0}$ in Figure 7(a) and the scraper \#1 moves from position 1 to position 2 . In our study, nodes 9,16 , and 3 of the fourth chute are chosen as the detecting points for vibration analysis. For convenient expression in the following, we mark the detecting nodes as measuring points \#1, \#2, and $\# 3$, respectively. Taking measuring point \#1 as the research example for description of the transmission process, the original signal is presented in Figure 7 (b). The vibration response presents a three-stage change, i.e., the acceleration phase, the steady phase, and the deceleration phase. As mentioned above, in the steady phase, the vibration signal can be treated as multiple segments with a time span of $\Delta T$, which corresponds to the chain assembly with a length of $\Delta L$ (Figure 5).

The field FPET of multiple monitoring points is carried out to obtain the vibration properties of the actual chute and evaluate the dynamic performance of the DTSM. The specifications of the experimental scraper conveyor correspond to SGB1200/3600 manufactured by Lianyungang Tianming Equipment Co., Ltd, and the running speed of the scraper chain is $1.0 \mathrm{~m} / \mathrm{s}$. In practical engineering, the actual double-drive transmission system is driven by two drive motors. The basic performance parameters are shown in Table 3. As shown in Figure 8, the experimental system mainly contains three acceleration sensors (TST120A1000), a wireless acquisition device (TST5925EV), a wireless receiver, and an on-site PC. The acceleration sensors are used for fixed-point measurements by detecting the vibration responses of measuring points \#1, \#2, and \#3 on the chute. The wireless acquisition device is used to collect experimental data in real time. In addition, the wireless receiver is intended for remote data transmission. The vibration data are stored in the on-site PC, and a sampling frequency of $1000 \mathrm{~Hz}$ is taken.

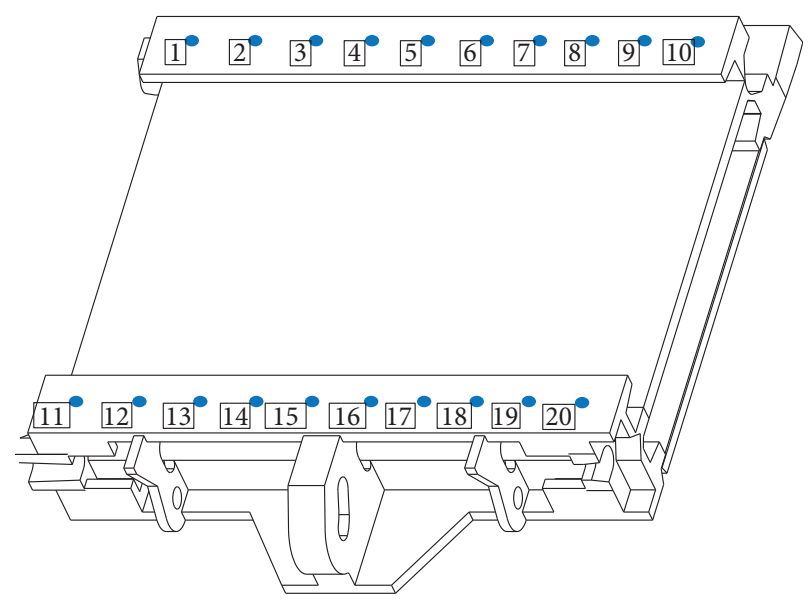

(a)

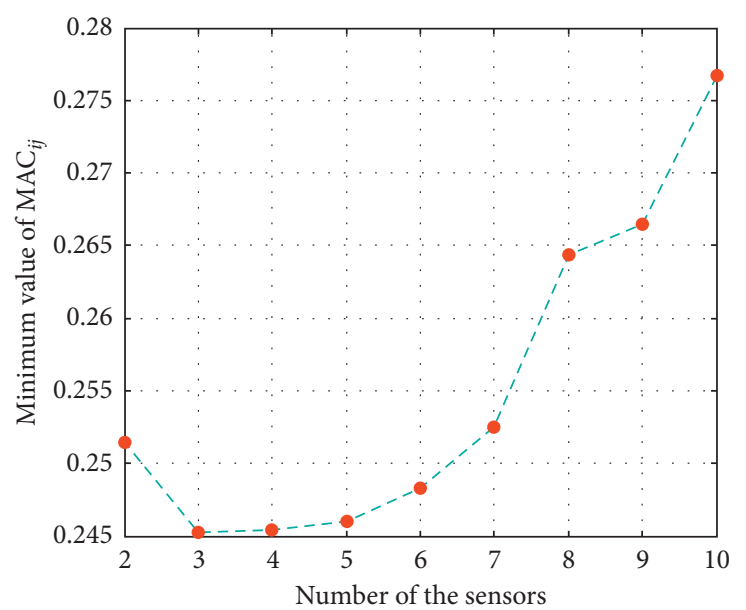

(b)

FIgURE 6: Description of the optimum placement scheme: (a) the primary measuring points; (b) the minimum $\mathrm{MAC}_{i j}$.

TABLE 2: Measuring points placement based on the MAC.

\begin{tabular}{lcc}
\hline Number & $f$ & Measuring points \\
\hline 2 & 0.2515 & 8,16 \\
3 & 0.2453 & $3,9,16$ \\
4 & 0.2454 & $1,3,9,16$ \\
5 & 0.2460 & $1,3,9,16,20$ \\
6 & 0.2483 & $1,3,9,10,11,16$ \\
7 & 0.2525 & $1,2,3,9,10,11,16$ \\
8 & 0.2644 & $1,3,8,9,10,11,15,16$ \\
9 & 0.2664 & $1,2,3,8,9,10,11,15,16$ \\
10 & 0.2767 & $1,2,3,8,9,10,11,15,16,20$ \\
\hline
\end{tabular}

Figure 9 shows the experimental and simulation signals of measuring points $\# 1, \# 2$, and $\# 3$ in the time span $\Delta T$. In the time domain, the simulation results and the experimental results are similar, which reflects the adaptability of the DTSM. Considering the nonlinear and time-varying characteristics of the vibration signals, the AOKR is used for time-frequency analysis.

The vibration signal of measuring point $\# 2$ in the time span $\Delta T$ is taken as the reference for time-frequency 


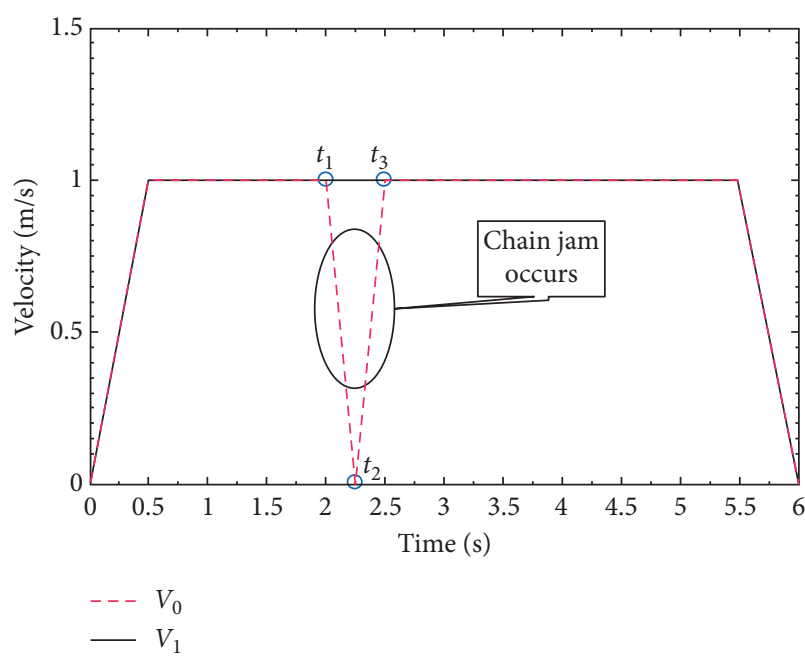

(a)

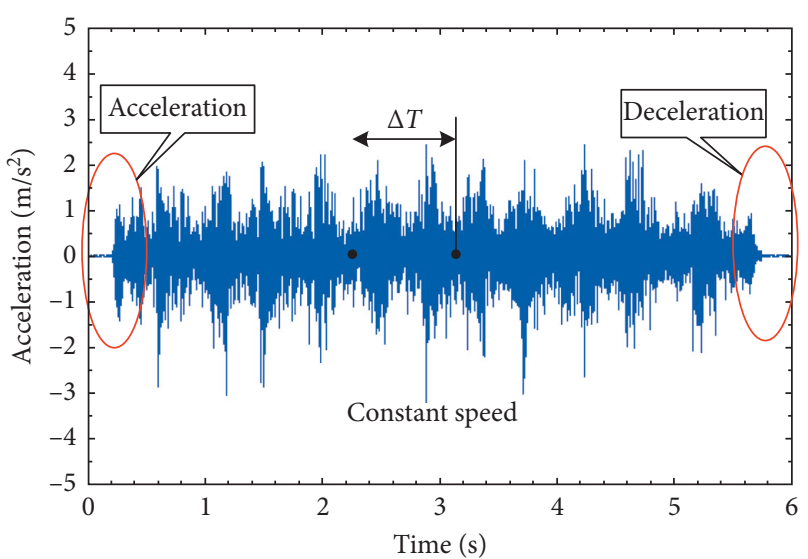

(b)

FIgURE 7: Transmission speed setting and vibration signal under normal condition.

TABle 3: Basic operating condition of the scraper conveyor.

\begin{tabular}{lccccc}
\hline Model & Chain size $(\mathrm{mm})$ & Conveyor width $(\mathrm{mm})$ & Chain speed $(\mathrm{m} / \mathrm{s})$ & Transport capacity $(\mathrm{t} / \mathrm{h})$ & Transport length $(\mathrm{m})$ \\
\hline SGZ1200/3600 & $\varphi 48 \times 152$ & $1750 \times 1180$ & $0 \sim 1.89$ & 3700 & 360 \\
\hline
\end{tabular}

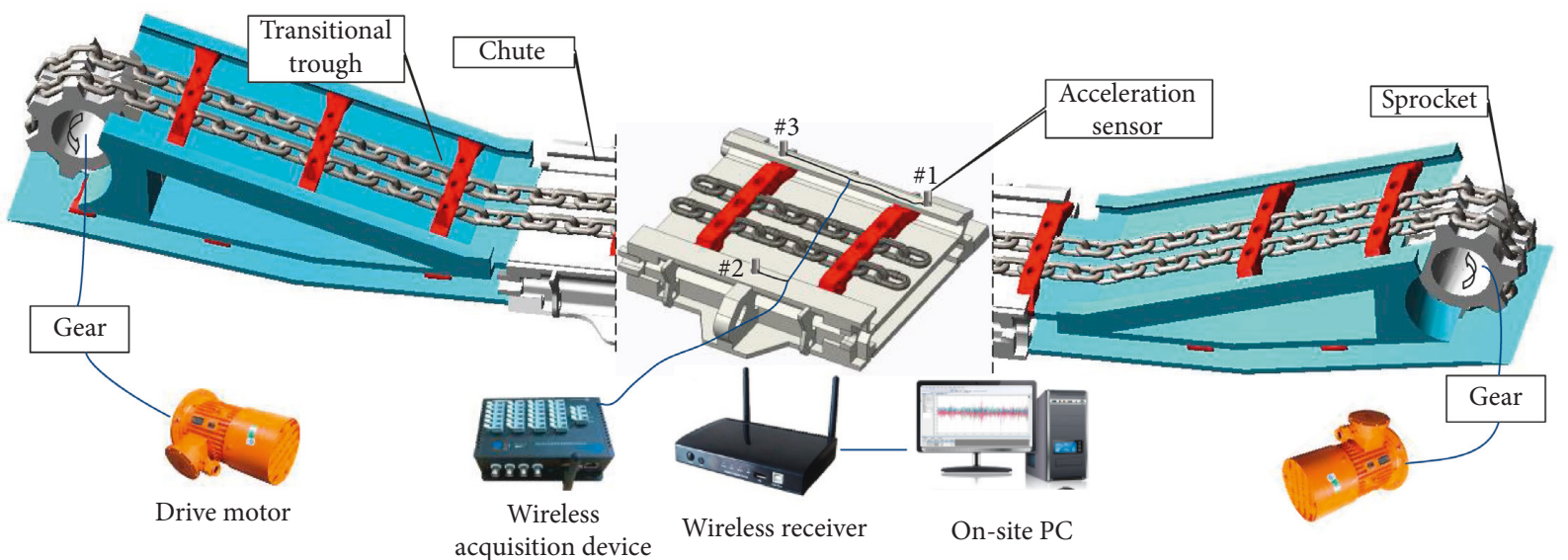

FIgURE 8: Experimental setup of the FPET.

analysis, and then the time-frequency representations of measuring points \#1 and \#3 in the same time period are demonstrated. Figure 10(a) shows the time-frequency representation of the experimental signals for different measuring points, and the power spectrum is also depicted. It presents that the vibration signal of the chute has a plurality of components. There are two major areas with strong frequency responses of the vibration signals for different measuring points: for measuring point \#1, the frequency range is $230-310 \mathrm{~Hz}$ and the time ranges are $0.15-0.30 \mathrm{~s}$ and $0.45-0.75 \mathrm{~s}$; for measuring point \#2, the frequency range is $230-340 \mathrm{~Hz}$ and the time ranges are $0.20-0.40 \mathrm{~s}$ and $0.55-0.70 \mathrm{~s}$; and for measuring point \#3, the frequency range is $225-330 \mathrm{~Hz}$ and the time ranges are $0.40-0.50 \mathrm{~s}$ and $0.70-0.90 \mathrm{~s}$. Considering the chain assembly in Figure 5, there are two scrapers for length $\Delta L$. In the actual transmission process, the two major areas with strong frequency responses are caused while the two scrapers passing through the measuring points. As shown, basic frequencies of the measuring points are 239, 278 and $249 \mathrm{~Hz}$, respectively. In addition, the peak of the vibration power spectrum is also presented, and the maximum values of the measuring points are 158.8, 156.1, and $149.9 \mathrm{~m}^{2}$ s.

Similarly, the time-frequency representation of the simulation signals with two major frequency responses is discussed. As Figure 10(b) indicates, for measuring points $\# 1$, \#2, and \#3, the vibration energies are concentrated at the frequency ranges $240-340,200-310$, and $200-320 \mathrm{~Hz}$, respectively. Correspondingly, for measuring point \#1, the 


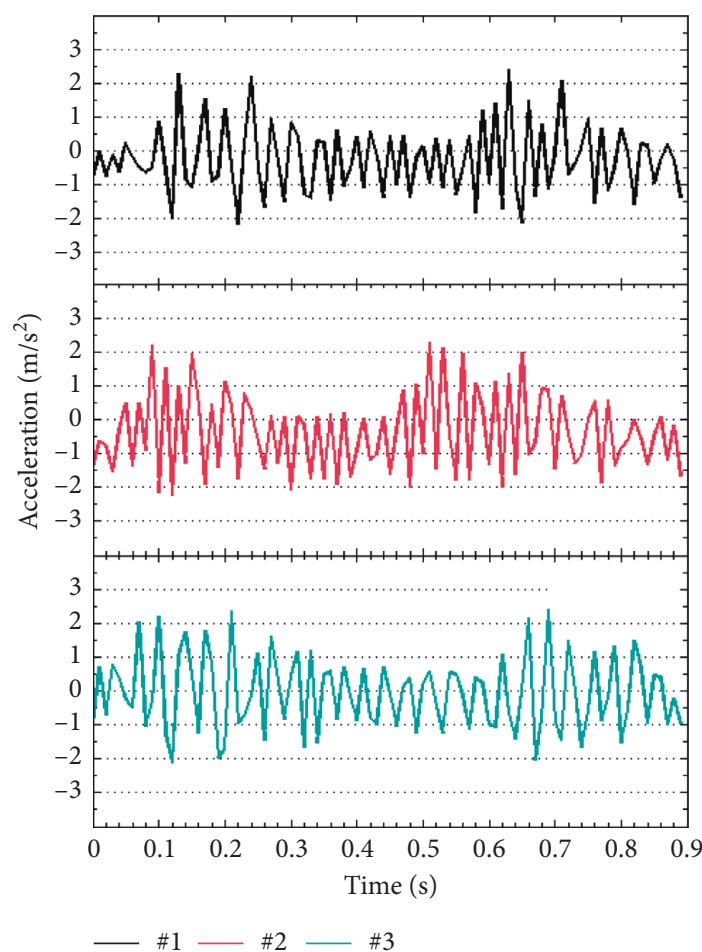

(a)

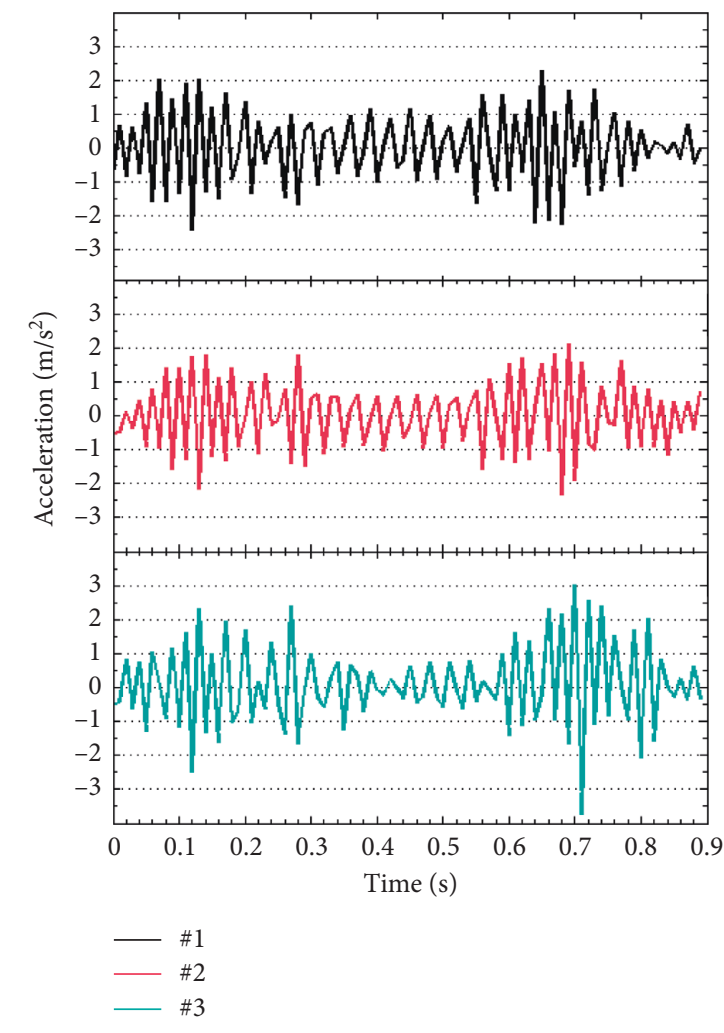

(b)

FIgURE 9: Vibration signals of different measuring points in $\Delta T$ : (a) experimental results; (b) simulation results.

time ranges are $0.10-0.25$ and $0.50-0.65 \mathrm{~s}$. Then the vibration energy of measuring point $\# 2$ is concentrated at the time ranges $0.15-0.45$ and $0.60-0.75 \mathrm{~s}$, and the time ranges of measuring point \#3 are $0.40-0.50$ and $0.70-0.85 \mathrm{~s}$. For the simulation signals, the basic frequencies of the measuring points are 281, 249, and $258 \mathrm{~Hz}$, respectively. The maximum values of vibration energies are 152.7, 148.9, and $153.2 \mathrm{~m}^{2}$ s, respectively. Considering the experimental results and the simulation results separately, good agreement between the main parameters of different measuring points is obtained. It also indicates that, in the same time period, the vibration signal has a delay characteristic for measuring points \#1, \#2, and \#3. This is possibly because that the measuring points are at different positions of the chute. Moreover, for different measuring points, the experimental signals and the simulation signals show good consistency in time-frequency characteristics. Hence, the established DTSM can efficiently simulate the actual production environment.

4.3. Fault Detection of the Scraper Chain. Based on the established DTSM, two typical failure patterns of the scraper chain are discussed, namely, chain jam and chain fracture. Three external load conditions are set, that is, empty load, half-load, and full-load conditions. The values of $W_{i}$ (Figure 5) are defined as $0,1 / 2 W_{0}$, and $W_{0}$, respectively. As designed in Figure 5, when chain jam occurs, the transmission speed $V_{i}$ is set as $V_{1}$ in Figure 7(a) and the failure time range is $t_{1}-t_{3}\left(t_{3}=2.5 \mathrm{~s}\right)$, the chain fault is triggered at $t_{1}=2 \mathrm{~s}$. Within the time range $t_{1}-t_{2}\left(t_{2}=2.25 \mathrm{~s}\right)$, the transmission speed $V_{i}$ decreases from 1 to $0 \mathrm{~m} / \mathrm{s}$. And the value of $V_{i}$ increases from 0 to $1 \mathrm{~m} / \mathrm{s}$ within the time range $t_{2}-t_{3}$. The whole process lasts $0.5 \mathrm{~s}$; the chain assembly is tightened, and the scraper chains are jammed. When chain fracture occurs, the transmission speed $V_{i}$ is set as $V_{0}$ in Figure 7(a). Moreover, as shown in Figure 5, the contact constraint between two contacting scraper chains at the labeled contact point \#1 is removed. As a result, the two contacting scraper chains will be separated. In order to ensure the accuracy of fault setting, the chain fracture is also triggered at $t_{1}=2 \mathrm{~s}$ and the contact constraint is removed in $0.5 \mathrm{~s}$, which is consistent with chain jam.

Considering both failure patterns of the scraper chain, our research focuses on the steady phase of the operation process within the time range 0.5 to $5.5 \mathrm{~s}$. In the steady phase, the vibration signals are obtained simultaneously at measuring points $\# 1, \# 2$, and \#3. Taking measuring point $\# 1$ as the case study, the vibration signals for chain jam and chain fracture under empty load condition are presented in Figures 11(a) and 11(b), respectively. After faults triggering, the vibration signals of the two failure patterns show a sudden increase after a short time delay. Subsequently, the signals exhibit unstable fluctuations at the time range $2.4-2.8 \mathrm{~s}$. In order to obtain a more detailed description of the detection results, the maximum amplitudes of the vibration signals under different working conditions are discussed, i.e., normal condition, chain jam, 


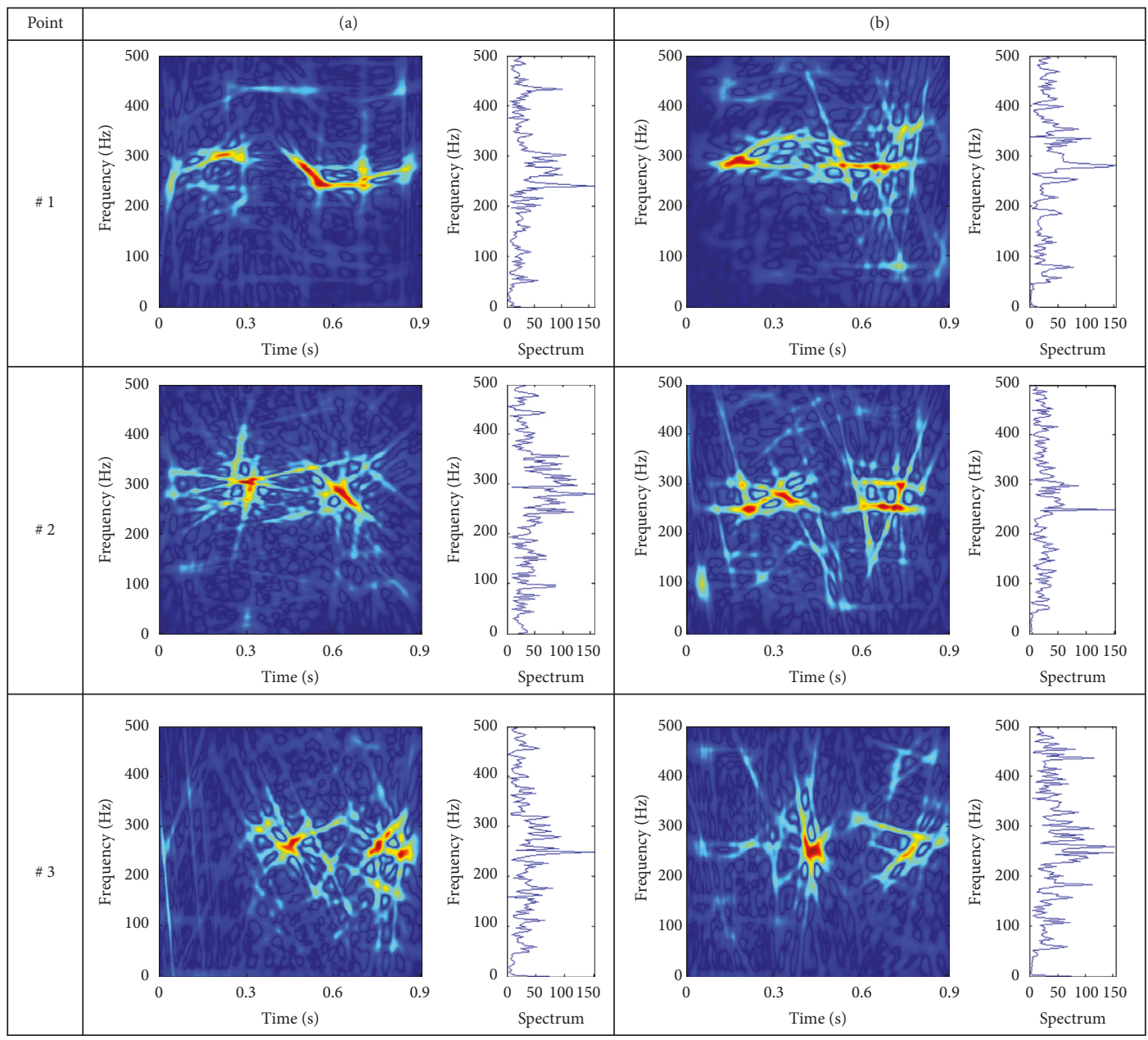

FIGURE 10: Time-frequency representation of vibration signals: (a) experimental results; (b) simulation results.

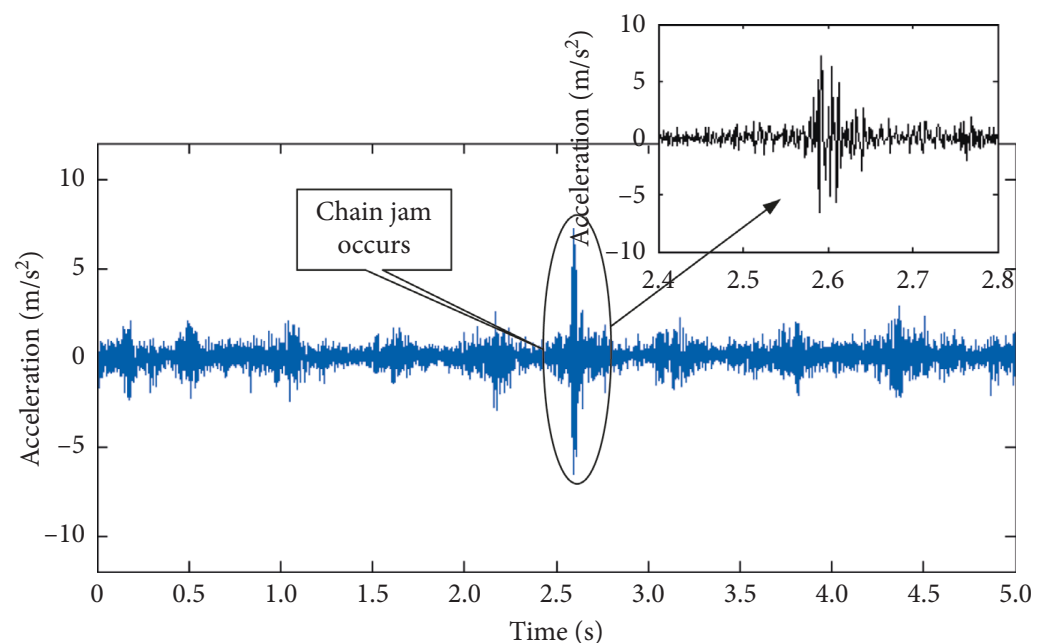

(a)

FIgURE 11: Continued. 


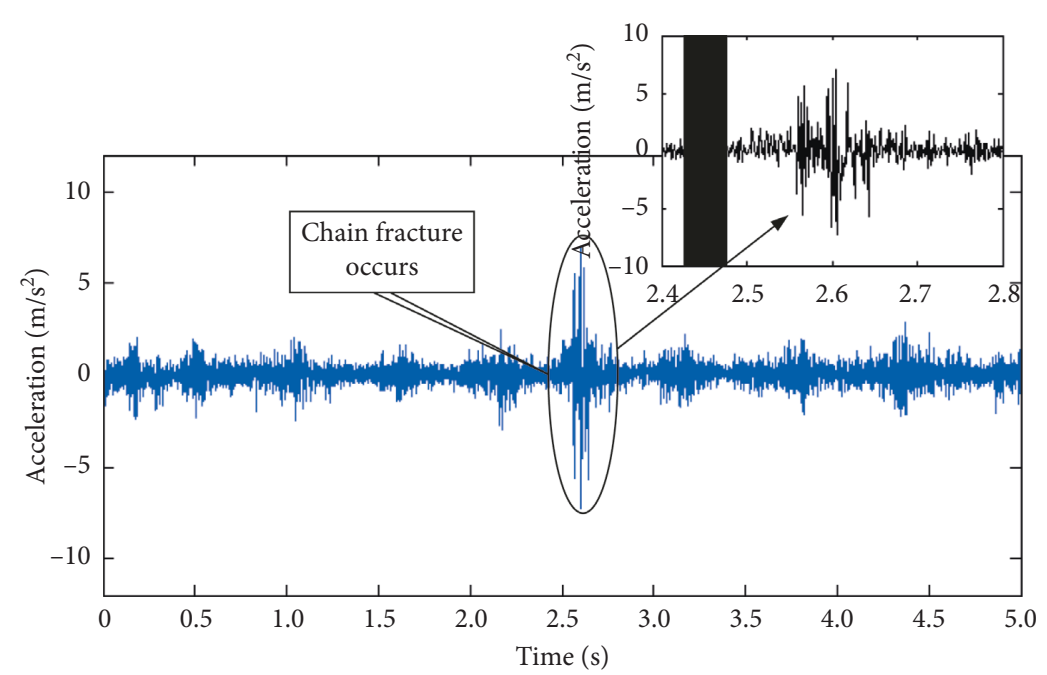

(b)

Figure 11: Vibration signals of the measuring point \#1 for (a) chain jam and (b) chain fracture.

and chain fracture. Wherein, the empty load, half-load, and full-load conditions are considered. The maximum amplitudes of the vibration signals at measuring points $\# 1$, \#2, and \#3 are depicted in Figures 12(a)-12(c), respectively.

Considering measuring point \#1, the maximum amplitudes of the vibration signals under empty load condition are $2.89,7.18$, and $6.98 \mathrm{~m} / \mathrm{s}^{2}$ under normal condition, chain jam, and chain fracture, respectively. Similarly, under halfload condition, the maximum amplitudes are $3.24,9.37$, and $9.56 \mathrm{~m} / \mathrm{s}^{2}$. Moreover, under full-load condition, the maximum amplitudes are 4.46, 11.06, and $10.82 \mathrm{~m} / \mathrm{s}^{2}$. With different external loads, the maximum amplitudes of the vibration signals for fault conditions are obviously higher than those for normal condition, and the difference between the amplitudes of the two typical failure patterns is small. For different fault conditions, with the increase of the external loads, the maximum amplitudes show trends to increase. The above statistical results are also applicable to measuring points \#2 and \#3. Therefore, chain faults can easily be detected by comparing the maximum amplitudes of the vibration signals, whereas the fault patterns are difficult to identify. According to the nonstationary and nonlinear characteristics of fault signals, the AOKR is utilized to analyze the vibration signals and classify failure patterns of the scraper chain. Within $1.5 \mathrm{~s}$ after faults triggering, the vibration signals at the three measuring points with different external loads are processed. Wherein, for chain jam and chain fracture under empty load condition, the time-frequency representations of vibration signals are presented in Figures 13(a) and 13(b), respectively.

The frequency components and frequency ranges of the same fault pattern are similar for different measuring points. As Figure 13(a) describes, the bright color between 0 and $50 \mathrm{~Hz}$ indicates one high energy area caused by chain jam. Then chain fracture can easily be distinguished according to the appearance of two high energy areas between 100 and $200 \mathrm{~Hz}$ as shown in Figure 13(b).
Observing the spectrum results, a more detailed description is given. When chain jam occurs, for measuring points \#1, \#2, and \#3, the high energy areas occur approximately at $0.5,0.75$, and $0.9 \mathrm{~s}$, respectively. Meanwhile, for chain fracture, the high energy areas include two main frequency components and are approximately concentrated at the time ranges $0.50-0.70,0.75-0.85$, and $1.0-1.15 \mathrm{~s}$, respectively. Hence, there is a delay characteristic of the fault occurrence, which is well in accordance with the conclusions in Section 4.2. In order to explore the influence of external loads on fault characteristics, the detailed differences of the fault patterns at measuring point \#2 are depicted in Figure 14. In fact, the external load has a great influence on the fault severity of both the failure patterns. Observing the spectrum results, the bright areas vary with the external loads. With increasing external load, the frequency ranges of the high energy areas become larger. Wherein, for chain jam under empty, half-, and full-load conditions, the frequency ranges are approximately $0-50,0-150$, and $0-250 \mathrm{~Hz}$, respectively. Meanwhile, for chain fracture, the frequency ranges are approximately $80-200,50-250$, and $50-350 \mathrm{~Hz}$, respectively.

In this part, three working conditions of the scraper chain are investigated above including normal condition, chain jam, and chain fracture. The vibration signals of measuring points $\# 1, \# 2$, and $\# 3$ on the detecting chute are analyzed, and the effects of the external loads on the vibration characteristics are discussed. Based on the above analysis, the occurrence of chain faults can easily be determined through amplitude comparisons of the original vibration signals. However, the observation confirms the similarity of the time domain waveforms of fault signals for chain jam and chain fracture. These two patterns of failures remain to be different through further processing by the AOKR, and the fault patterns can be distinguished according to the number of high energy areas of the time-frequency representation of vibration signals. In conclusion, the 


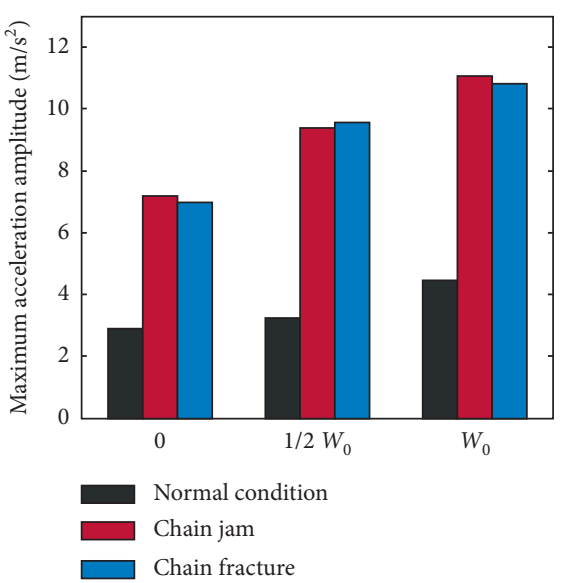

(a)

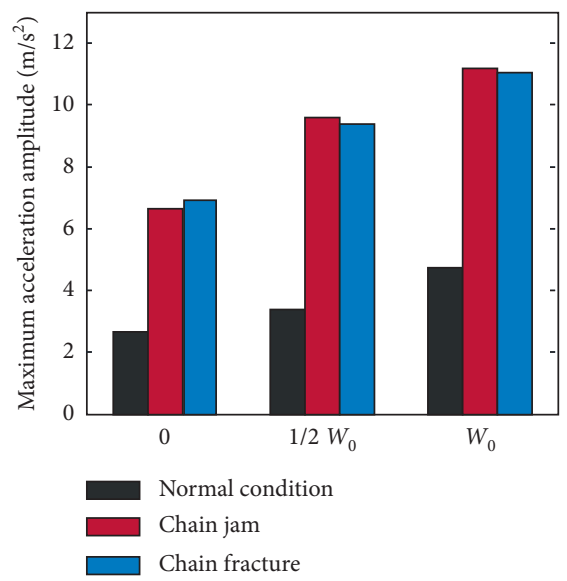

(b)

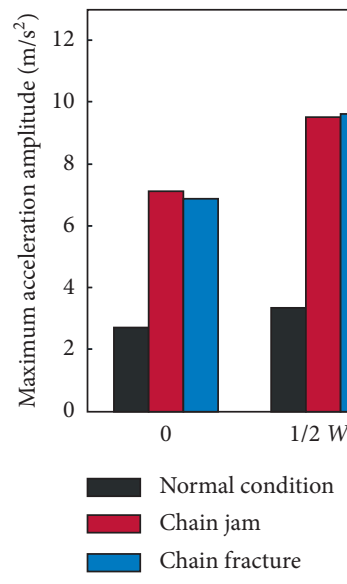

(c)

Figure 12: Statistical results of the maximum vibration amplitude at different measuring points: (a) \#1; (b) \#2; (c) \#3.

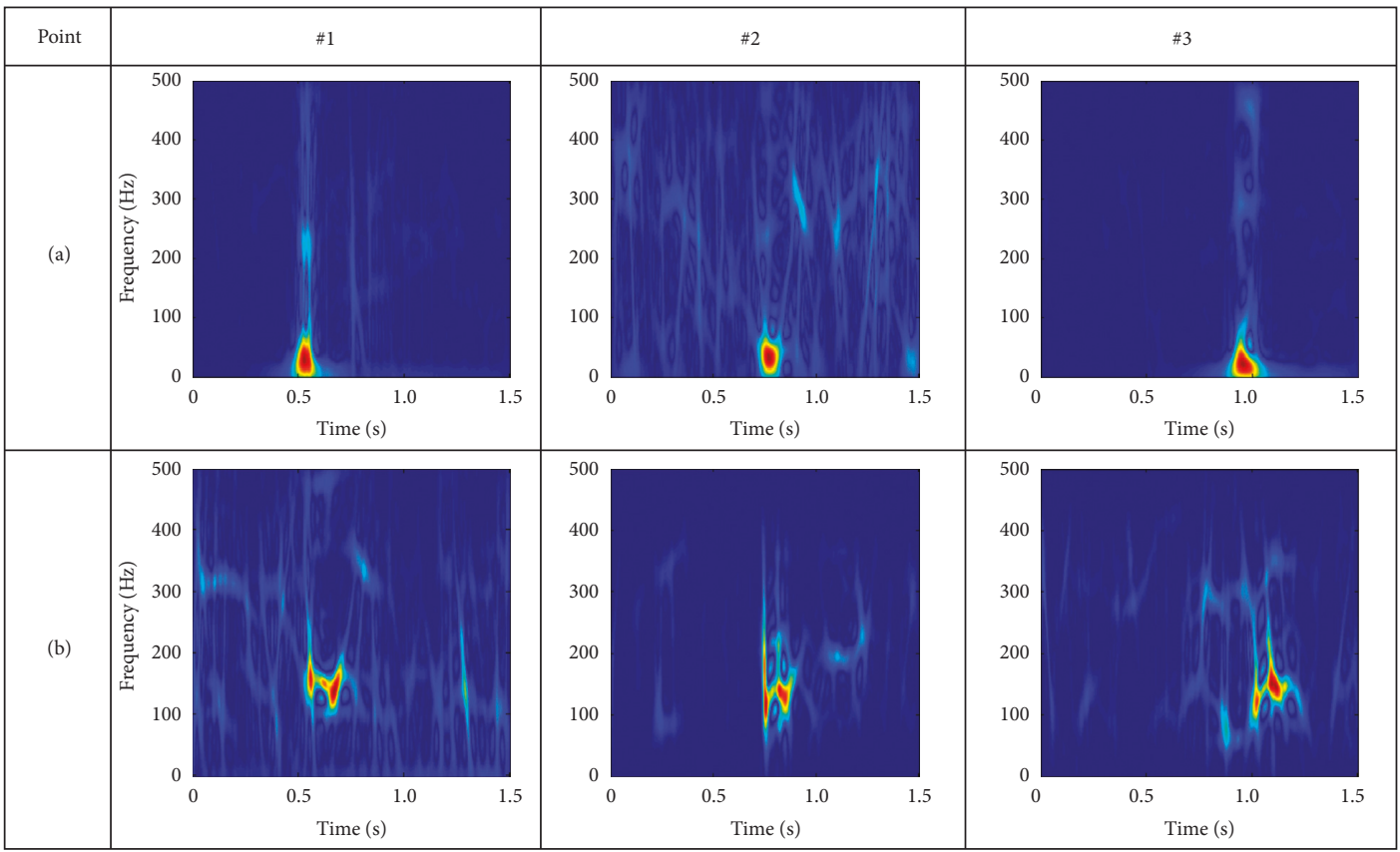

FIGURE 13: Time-frequency representation of vibration signals under empty load: (a) chain jam; (b) chain fracture. 


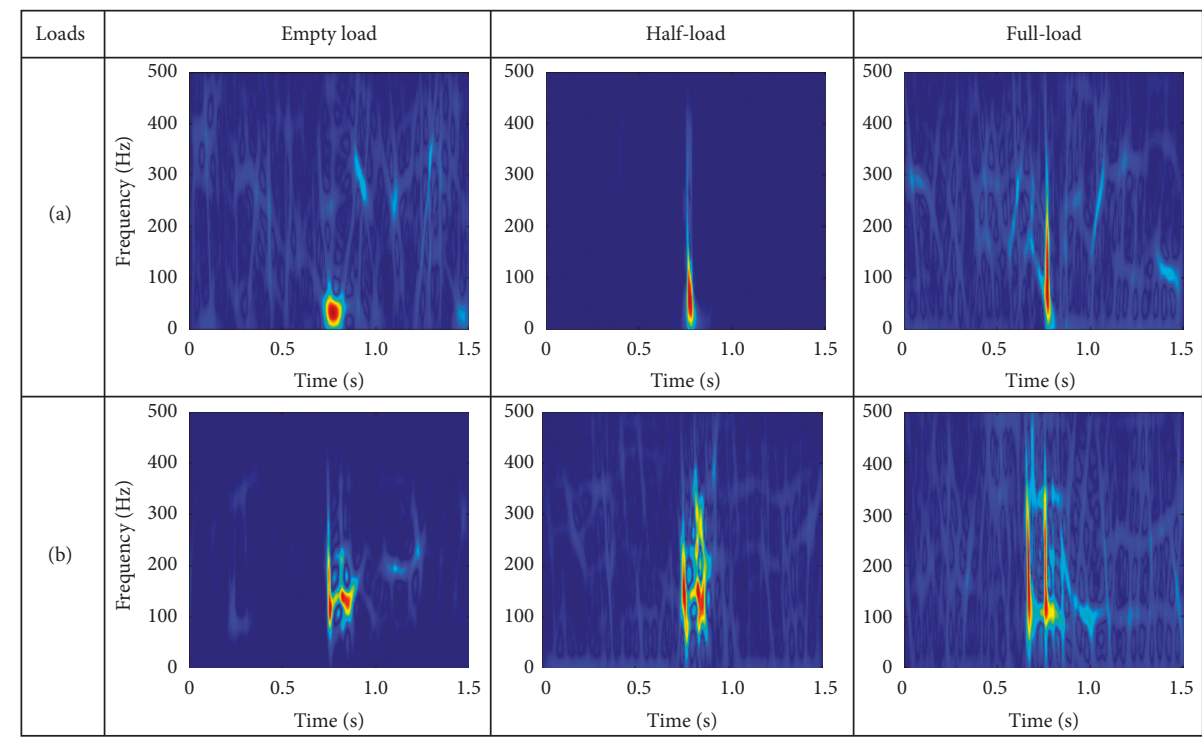

FIGURE 14: Time-frequency representation of vibration signals at measuring point \#2 with different external loads: (a) chain jam; (b) chain fracture.

proposed detection strategy is effective at detecting the occurrence of chain faults and identifying the failure patterns under different operating conditions.

\section{Conclusions}

During the actual operation, the working state of the scraper chain can reflect the dynamic performance of the scraper conveyor. To address the difficulties with direct sensor measurement for parameters of the moving scraper chain, a novel strategy for fault detection of the scraper chain based on vibration analysis of the chute was proposed. Based on modal analysis and the MAC, the measuring points of vibration signals on the chute were determined. To fit the actual behavior of the transmission process, the DTSM was presented based on finite element modeling, and the correctness of the dynamic model was verified by comparison with the FPET. Then the vibration properties of the measuring points on the chute under normal condition, chain jam, and chain fracture were discussed. Moreover, the occurrence of chain faults were determined by comparing the amplitudes of the vibration signal in the time domain, while the AOKR was utilized for time-frequency representation of vibration signals and distinguishing the two typical failure patterns. Furthermore, the strategy verification based on experimental data will be taken into consideration in the near future.

\section{Data Availability}

The data used to support the findings of this study are available from the corresponding author upon request.

\section{Conflicts of Interest}

The authors declare that they have no conflicts of interest.

\section{Acknowledgments}

This work was supported by the Key Project of National Natural Science Foundation of China (U1510205), Natural Science Foundation of Jiangsu Province (No. BK20160251), Xuzhou Research program (KC14H0138), Fundamental Research Funds for the Central Universities (2014Y05), and Project Funded by the Priority Academic Program Development of Jiangsu Higher Education Institutions (PAPD).

\section{References}

[1] C. D. Brown, "Design, build and test of a longwall armoured face conveyor," Longwall Mining, 2002.

[2] M. Dolipski, P. Cheluszka, E. Remiorz, and P. Sobota, "Follow-up chain tension in an armoured face conveyor/ nadążne napinanie lańcucha zgrzebłowego W przenośniku scianowym," Archives of Mining Sciences, vol. 60, no. 1, pp. 25-38, 2015.

[3] L. A. Morley, J. L. Kohler, and H. M. Smolnikar, "A model for predicting motor load for an armored face-conveyor drive," IEEE Transactions on Industry Applications, vol. 24, no. 4, pp. 649-659, 1988.

[4] A. A. Ordin and A. A. Metel'kov, "Analysis of longwall face output in screw-type cutter-loader-and-scraper conveyor system in underground mining of flat-lying coal beds," Journal of Mining Science, vol. 51, no. 6, pp. 1173-1179, 2015.

[5] B. He, G. Li, H. Shi et al., "Dynamic behaviour modelling and simulation of the chain transmission system for an armoured face conveyor," in Proceedings of the IEEE 10th International Conference on Computer-Aided Industrial Design and Conceptual Design, CAID \& CD 2009, pp. 1000-1004, Beijing, China, November 2009.

[6] R. Nie, B. He, P. Yuan, L. Zhang, and G. Li, "Novel approach to and implementation of design and analysis of armored face conveyor power train," Science China Technological Sciences, vol. 58, no. 12, pp. 2153-2168, 2015. 
[7] R. Nie, B. He, L. Zhang, and G. Li, "Modelling of the transmission system in conveying equipment based on Euler method with application," Proceedings of the Institution of Mechanical Engineers, Part K: Journal of Multi-body Dynamics, vol. 228, no. 3, pp. 294-306, 2014.

[8] S. B. Jiang, X. Zhang, K. D. Gao, J. Gao, Q. Y. Wang, and K. Hidenori, "Multi-body dynamics and vibration analysis of chain assembly in armoured face conveyor," International Journal of Simulation Modelling, vol. 16, no. 3, pp. 458-470, 2017.

[9] M. Myszkowski and D. Loehning, "Chain force measurements on armoured face conveyors and coal plows in heavyduty longwalls," CIM Bulletin, vol. 94, no. 1054, pp. 72-75, 2001.

[10] H. Wang, Q. Zhang, and F. Xie, "Dynamic tension test and intelligent coordinated control system of a heavy scraper conveyor," IET Science, Measurement and Technology, vol. 11, no. 7, pp. 871-877, 2017.

[11] S. Sen, M. X. Min, and Y. Z. She, "Diagnosis of coal scraper conveyor based on Fuzzy Fault tree," in Proceedings of the 2015 Seventh International Conference on Measuring Technology and Mechatronics Automation (ICMTMA), pp. 392395, IEEE, Nanchang, China, June 2015.

[12] S.-s. Xue, X.-c. Li, and X.-y. Xu, "Fault tree and Bayesian network based scraper conveyer fault diagnosis," in Proceedings of the 22nd International Conference on Industrial Engineering and Engineering Management 2015, pp. 783-795, Atlantis Press, Paris, France, January 2016.

[13] X. Gong, X. Ma, Y. Zhang et al., "Application of fuzzy neural network in fault diagnosis for scraper conveyor vibration," in Proceedings of the 2013 IEEE International Conference on Information and Automation (ICIA), pp. 1135-1140, IEEE, Yinchuan, China, August 2013.

[14] Y. Zhang, X. Ma, Y. Jianxiang et al., "Fuzzy neural network fault diagnosis and online vibration monitoring system for the coal scraper conveyor based on rough set theory," in Proceedings of the 2013 32nd Chinese Control Conference (CCC), pp. 6134-6138, IEEE, Xi'an, China, July 2013.

[15] B. Zhang, A. C. C. Tan, and J.-h. Lin, "Gearbox fault diagnosis of high-speed railway train," Engineering Failure Analysis, vol. 66, pp. 407-420, 2016.

[16] E. Parloo, P. Verboven, P. Guillaume, and M. Van Overmeire, "Autonomous structural health monitoring-part ii: vibrationbased in-operation damage assessment," Mechanical Systems and Signal Processing, vol. 16, no. 4, pp. 659-675, 2002.

[17] C. S. Sakaris, J. S. Sakellariou, and S. D. Fassois, "Randomvibration-based damage detection and precise localization on a lab-scale aircraft stabilizer structure via the Generalized Functional Model Based Method," Structural Health Monitoring: An International Journal, vol. 16, no. 5, pp. 594-610, 2017.

[18] Y. Zhang, W. Song, M. Karimi, C.-H. Chi, and A. Kudreyko, "Fractional autoregressive integrated moving average and finite-element modal: the forecast of tire vibration trend," IEEE Access, vol. 6, pp. 40137-40142, 2018.

[19] M. Pastor, M. Binda, and T. Harčarik, "Modal assurance criterion,” Procedia Engineering, vol. 48, pp. 543-548, 2012.

[20] W. J. Staszewski, K. Worden, and G. R. Tomlinson, "Timefrequency analysis in gearbox fault detection using the Wignerville distribution and pattern recognition," Mechanical Systems and Signal Processing, vol. 11, no. 5, pp. 673-692, 1997.

[21] J.-D. Wu and P.-H. Chiang, "Application of Wigner-Ville distribution and probability neural network for scooter engine fault diagnosis," Expert Systems with Applications, vol. 36, no. 2, pp. 2187-2199, 2009.

[22] Z. Feng and M. Liang, "Fault diagnosis of wind turbine planetary gearbox under nonstationary conditions via adaptive optimal kernel time-frequency analysis," Renewable Energy, vol. 66, pp. 468-477, 2014. 


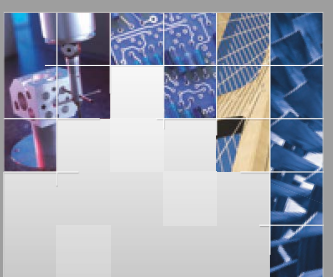

\section{Enfincering}
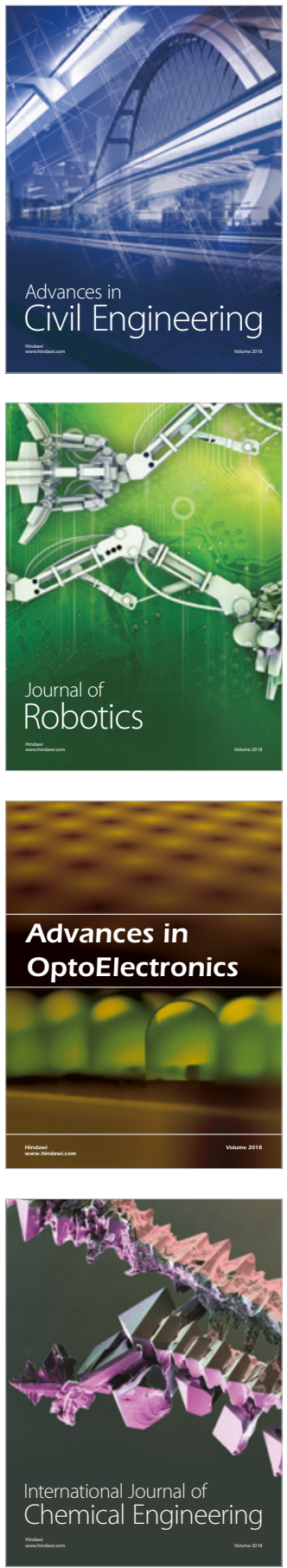

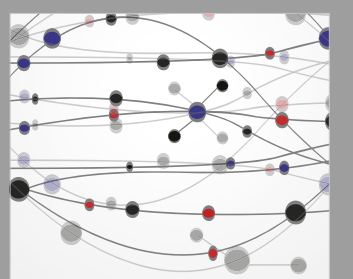

\section{Rotating \\ Machinery}

The Scientific World Journal

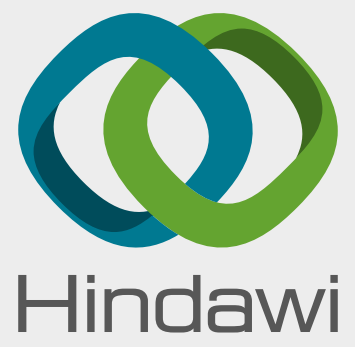

Submit your manuscripts at

www.hindawi.com
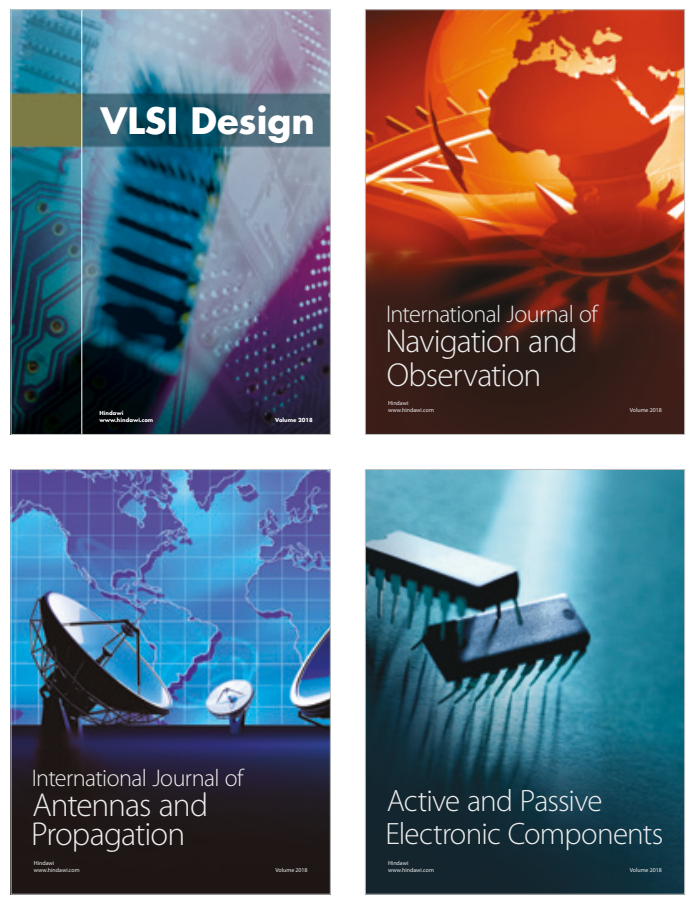
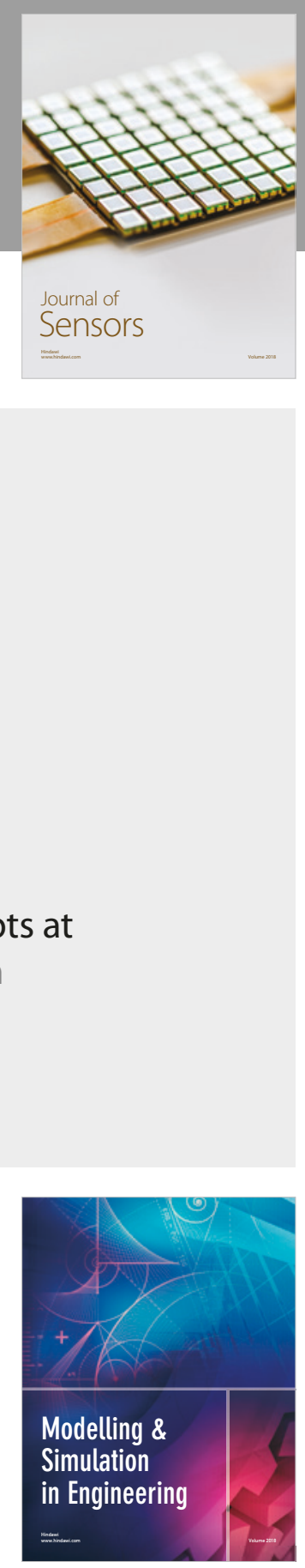

\section{Advances \\ Multimedia}
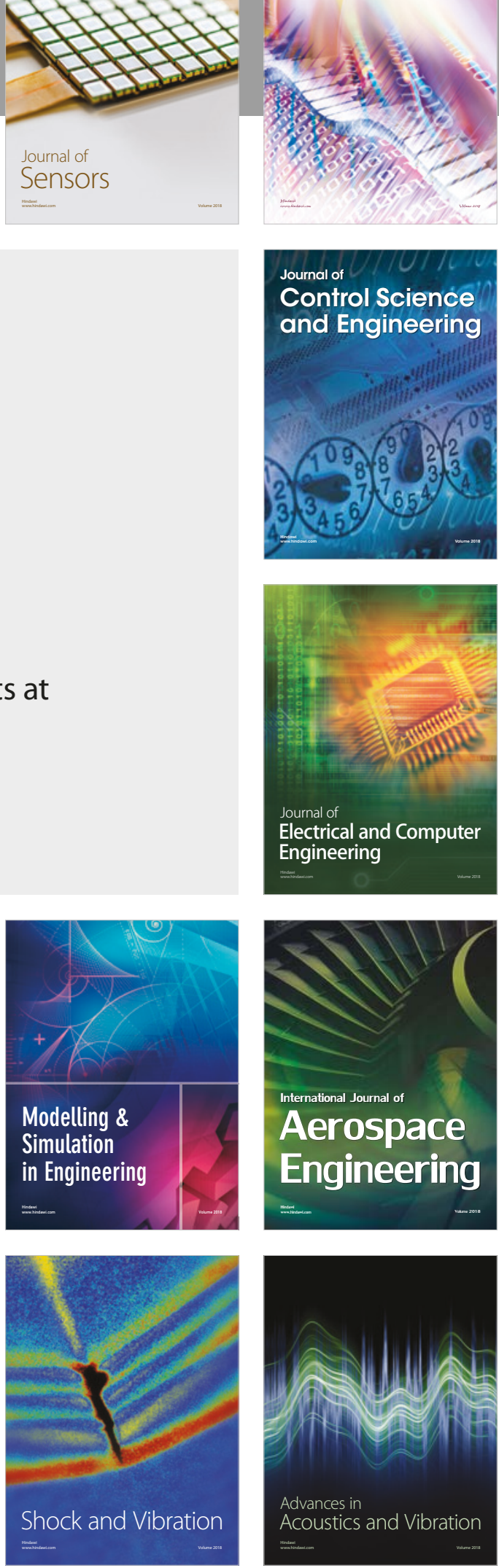